NASA Technical Memorandum 86876

\title{
Ultrasonic Nondestructive Evaluation, Microstructure, and Mechanical Property Interrelations
}

Alex Vary

Lewis Research Center

Cleveland, Ohio

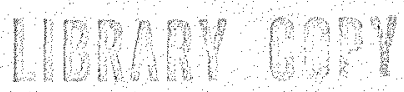

$1 \mathrm{H}$

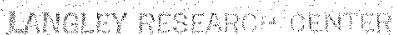

DBNAEY MBSA

HWMTON WROWA

October 1984

\section{NNSA}


Page

INTRODUCTION . . . . . . . . . . . . . . . . . . . . 1

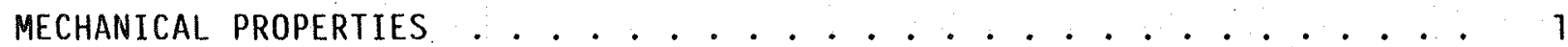

Elastic Moduli. . . . . . . . . . . . . . . . . . . . 2

Tensile and Shear Strength ................. 2

Fracture Toughness . . . . . . . . . . . . . . . . . 3

Property Degradation . . . . . . . . . . . . . . . . 3

MICROSTRUCTURE . . . . . . . . . . . . . . . . . . . . . . . . 4

Characterization of Microstructure . . . . . . . . . . . . . . . 4

Mechanical Properties and Microstructure . . . . . . . . . . . 5

ULTRASONIC METHODS . . . . . . . . . . . . . . . . . . . . 5

Pulse-Echo Method . . . . . . . . . . . . . . . . . . 6

Acousto-U1trasonic Method .................. 6

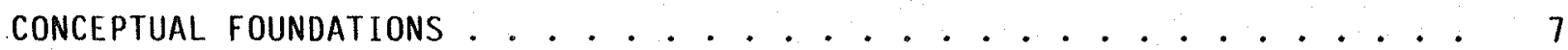

Empirical Approaches ..................... . . . 7

Conceptual Models . . . . . . . . . . . . . . . . . . . . . 8

Stress Wave Interaction (SWI) Model .............. . 9

Microstructure Transfer Function (MTF) Model . . . . . . . . . . 9 9

Microcrack Nucleation Mechanics (MNM) Model ............ 11

EXPERIMENTAL VERIFICATION . . . . . . . . . . . . . . . . 12

SUMMARY . . . . . . . . . . . . . . . . . . . . . . 13

CONCLUSION . . . . . . . . . . . . . . . . . . . . . 13

REFERENCES .................................... 14 
ULTRASONIC NONDESTRUCTIVE EVALUATION, MICROSTRUCTURE, AND MECHANICAL PROPERTY INTERRELATIONS

\author{
Alex Vary \\ National Aeronautics and Space Administration \\ Lewis Research Center \\ Cleveland, ohio 44135
}

\title{
INTRODUCTION
}

There is a requirement for NDE (nondestructive evaluation) technology for measuring variations in microstructure, associated extrinsic properties (e.g., strength, toughness), and diffuse flaw populations that govern the mechanical performance of a part or structure. Specification of flaw criticality and prediction of structural reliability depend on knowing mechanical properties and morphological conditions: elastic moduli, strength, fracture toughness, hardness, porosity, phase structure, fatigue and creep damage, etc. Fracture analysis and life prediction models assume flaw initiation and growth in materials with known moduli, strengths, toughnesses, and morphological conditions. It is possible to use uitrasonic NDE techniques to verify whether a structure possesses the properties assumed in design analysis. It will be shown herein that this can be done by analyzing signal modulating effects of material microstructures.

Various kinds of NDE technology can be used to characterize mechanical properties, e.g., electromagnetic, radiometric, ultrasonic (McMaster, 1959; Green, 1973a; Vary, 1973; Krautkramer and Krautkramer, 1977; Hayward, 1978). This paper considers only ultrasonic techniques for measuring mechanical properties. The speed of wave propagation and wave energy loss underly ultrasonic mechanical property determinations. Accordingly, ultrasonics depends on measuring physical and acoustical properties via the interaction of elastic stress waves with microstructural and morphological factors (Mason, 1958; Kolsky 1963; $\mathrm{Fu}$, 1982).

There is an established theoretical foundation and empirical basis for ultrasonic measurement of elastic moduli (Truell et al. 1969; Schreiber, et al. 1973). Conversely, ultrasonic assessment of mechanical properties 1ike strength and toughness are currently based primarily on empirical correlations (Vary 1978a; 1980a). This paper reviews the relevant literature and describes new conceptual foundations for some of the empirical correlations.

Three conceptual models are described: (1) a stress wave interaction mode 1, (2) a microstructure transfer function mode1, and, (3) a microcrack nucleation mechanics model. These conceptual models are applied to ultrasonic assessment of fracture toughness to illustrate an approach for explaining and predicting empirical correlations found among uitrasonic measurements, microstructure, and mechanical properties.

\section{MECHANICAL PROPERTIES}

U1trasonic materials characterization may be divided into two major categories. The first category pertains to measurements that are related to mechanical properties, e.g., elastic moduli, tensile strength, yield strength, 
fracture toughness. The second category pertains to material conditions that govern mechanical properties and dynamic response, e.g., microstructure, morphology (grain size, shape, distribution).

Examples of ultrasonic materials characterization from both above mentioned categories are reviewed in this and the next section. This review is selective rather than exhaustive since it is meant to highight specific areas of materials characterization technology that require the new concepts advanced later in this paper. For further reviews see Papadakis (1976), Vary (1978a; 1980a), and Fu (1982).

\section{Elastic Moduli}

The measurement of elastic moduli is fundamental to understanding and predicting material behavior. Because they are related to interatomic forces, elastic moduli govern attainable strengths. Elastic moduli also govern the strain energy release rate and the stress wave propagation properties associated with shock, impact, fracture, etc.

Brittle materials generally require ultrasonic velocity measurements to evaluate elastic modlui. This is particularly true for ceramics where velocity measurements are needed to determine elastic moduli since other methods (tensile tests) produce either poor or no results. Moduli of brittle solids are easier to determine ultrasonically because they exhibit very small strains under tension.

Ledbetter, et al. (1980, 1981) have applied longitudinal and transverse ultrasonic velocity measurements to assessments of the variability of elastic moduli in stainless steels and pioneered the application of their techniques to measurement of elastic moduli in stainless steels at cryogenic temperatures.

Lockyer and Proudfoot (1970) obtained excellent linear correlations between ultrasonic moduli and tensile moduli with brittle graphites and sintered tungsten. Simflar relations were obtained by Proudfoot (1970) for fiber reinforced composites. Kreher, et al. (1977) demonstrated relations among transverse and longitudinal velocities and elastic moduli of porous ceramics.

For anisotropic materials ultrasonic measurements of modli can complement strength analyses and theory verification (Smith, 1972). Anisotropy, symmetry, homogeneity, misorientation, and similar morphological factors having a bearing on modulus (hence on strength variations) can be assessed velocity measurements.

\section{Tensile and Shear Strength}

The mechanical strengths of some types of brittle materials correlate directly with elastic constants. Because the tensile modulus may be determined from longitudinal and transverse velocities, ultrasonics can form the basis for correlations with the tensile strengths of materials such as concrete, ceramics, and some composities.

Schultz (1971) found correlations among flexural modulus, flexural strength, and ultrasonic velocity in fiber reinforced composities. Good agreement between theory and experimental data relating ultrasonic moduli and 
strength were reported by Smith (1972) for carbon fibers and their composites. Zurbrick, (1973) used velocity measurements to correlate tensile strengths and ultrasonic moduli in materials ranging from glass/epoxy to boron/aluminum fiber composites.

There are cases where more than one type of NDE measurement is needed to determine a mechanical property. For example, the tensile strength of cast iron can be deduced from velocity and Brine 11 hardness measurements (Krautkramer and Krautkramer, 1977). Thus, by combining two independent NDE methods, a key property can be verified better than by either method alone.

Metal-to-metal adhesive bond strengths have been determined with ultrasonic resonant frequency measurements in the adhesive layers (Schliekelmann, 1973). Assessments of adhesive bonds and composite laminate strengths have been made by means of frequency spectrum analyses of echoes returned from bond interfaces (Lloyd, 1974, Adlers, et al. 1977; Flynn, 1977).

The "acousto-ultrasonic" method (described hereinafter) has been used to establish correlations with interlaminar shear strengths and tensile strengths in composite laminates (Vary and Bowles, 1979; Vary, 1982). The acoustoultrasonic method was used to rank composite laminates according to their ultimate tensile strengths (Vary and Lark, 1979), (fig. 1). By using the acousto-ultrasonic method Vary and Bowles (1977) demonstrated a parametic approach for estimating interlaminar shear strength in fiber composite laminates, (fig. 2) (see Empirical Approaches).

\section{Fracture Toughness}

Ultrasonic methods for determining the fracture toughness of structural materials is of high interest. A major incentive is the need for rapid, inexpensive methods to verify toughness and related mechanical properties prior to placing critical parts in service or after the parts have been exposed to service.

UTtrasonic measurement of toughness has been demonstrated (Vary, 1978b; Vary and Hul1, 1982). Empirical correlations were found between ultrasonic attenuation factors and fracture toughness as measured by the "drop weight tear test" and the Palmqvist methods, (figs. 3 and 4 ), respectively. A theoretical basis for these empirical correlations will be discussed in detail later.

\section{Property Degradation}

Many fiber reinforced composites are prone to mechanical and thermochemical degradation. Strength loss in fiber reinforced plastics can follow moisture ingress, for example. Lowering of interlaminar shear strengths from hydrothermal aging of graphite fiber composites was detected by ultrasonic velocity measurements (Kaelble and Dynes, 1977a; 1977b; Meron, et a1., 1977).

Early detection of cyclic fatigue damage in metals has been the object of ultrasonic studies. Green (1973b) described the complementary use of ultrasonic attenuation and acoustic emission measurements to monitor fatigue effects. Surface wave velocity measurements have been proposed for detecting imminent fatigue failure (Rasmussen, 1962; Martin and Tsang, 1970). 
Williams, et al. (1980; 1982) found correlations between ultrasonic attenuation and fatigue in graphite/epoxy laminates, (fig. 5). The acoustoultrasonic method was used by Duke, et a1. (1983) to show covariation of the stress wave factor with secant modulus and fatigue damage in graphite/epoxy laminates, (fig. 6).

\section{MICROSTRUCTURE}

There are two aspects to the NDE of material microstructure. One of these aspects is simply the characterization of microstructural features (grain size, shape, distribution; voids, porosity; inclusions; etc.). The other aspect is the correlation of microstructure and morphology with mechanical properties.

\section{Characterization of Microstructure}

The effects of microstructure can impede effective ultrasonic flaw detection. The detection of extremely small critical flaws may be hampered by "grain noise" or backscatter. From the perspective of materials characterization this "noise" can be quite useful since it reveals much about the nature of the microstructure. Backscattered ultrasonic signals can be used to determine cleanliness of steel, e.g., degree of freedom from slag, debris, inclusions, (Schlengermann, 1974). Goebbels (1980) describes an ultrasonic backscatter method for determination of grain size in steel as an alternative to metallography.

Among the methods for assessing microstructure is that of measuring scatter attenuation due to the grain structure of polycrystalline solids. In these solids, studies of the relation of grain size to ultrasonic attenuation have produced empirical formulas and scattering constants. Papadak is (1964b; 1965a) has developed extensive tabulations of scatter attenuation constants for cubic and other polycrystalline solids. Variations in ultrasonic velocity also correlate with grain size in some materials (Papadakis, 1970, 1976). Application of attenuation and velocity measurements to various steels produced correlations with grain size, second phase content, and anisotropy (Murray, 1969, Juva and Haarvisto, 1977; KTinman, et a1. 1980).

An area of special interest is verification of theoretically predicted relations between ultrasonic attenuation coefficients and grain or second phase particle size, see Evans, et al. (1978), Serabian and Williams (1978), and Papadakis (1981). Theoretical relations are rarely realized with microstructures that consist of polycrystalline aggregates. Further development of theory for multiple scattering of ultrasonic waves is required. When fully developed, the theory will enable more accurate characterizations of real (versus idealized) microstructures.

Evaluation of structural ceramics of current technological interest presents some special problems. Micron-size voids, cracks, and inclusions can be quite serious flaws in ceramics. Microflaw populations are usually distributed throughout the bulk of a ceramic article and thus affect bulk properties. Ultrasonic methods are useful to assess ceramic bulk property variations due to diffuse populations of these micron-size voids, cracks, etc.

Ultrasonics methods can detect detrimental density changes, porosity, and similar deficiencies in fine grained sintered and reaction-bonded ceramics. 
For example, Klima et al. (1981) found that velocity increases with density in sintered ceramics, (fig. 7). The theoretical inverse relation of velocity to density, found with fully densified materials (Green 1973a), cannot be assumed for porous materials. In composites and ceramics microvoid and pore size, shape, and orientation govern anisotropies in velocity and strength properties (Kreher, et a1. 1977).

Microvoid populations exceeding only a few volume percent in fiber composites can significantly reduce mechanical strength. Relations among ultrasonic attenuation, microvold content, and fiber composite interlaminar shear strength have been reported by Martin (1977). Using through transmitted ultrasound it was shown that increased attenuation corresponds to greater void content and lower interlaminar shear strength (Stone and Clarke, 1975; Jones and Stone, 1976; Stone, 1978).

While quantitative evaluations of microstructure usually employ velocity and attenuation measurements some recent work has illustrated the usefulness of ultrasonic microscopy (Szilard and Scruton, 1974; Kessler, 1974). Subsurface microstructures of solids have been investigated using photo-acoustic microscopy, i.e., with laser excitation of ultrasonic waves (Wong, et al. 1978; Thomas, et al. 1980). Microstructure in amorphous as well as polycrystalline solids has been quantitatively characterized with ultrasonic spectroscopy (Gericke, 1970; Brown 1973; Fitting and Adler, 1981).

\section{Mechanical Properties and Microstructure}

Ultrasonic evaluation of mechanical properties depends on the characterization of material microstructure. Figures 3 and 4 illustrate the dependence of mechanical properties on microstructure (grain size, second phase constituents, etc.). Inferences of material properties and predictions of dynamic response have long been based on metallographic and other methods that reveal material microstructure and morphology. Ultrasonic methods are alternatives to these conventional approaches.

The previous illustrative examples of the correlations among ultrasonic measurements and mechanical properties demonstrate the influence of microstructure. An approach to ultrasonic materials characterization lies in the analysis of stress wave interactions with microstructure. Microstructure and material morphology are factors that govern material properties and also ultrasonic wave propagation modes (velocity, attenuation). It should be expected that both velocity and attenuation measurements will correlate with the mechanical properties and dynamic response of materials.

The remainder of this paper explores a basis for the interrelation of ultrasonic, microstructura1, and mechanical property factors. This paper focuses on fracture toughness, a property for which an excellent case can be advanced regarding the aforementioned interrelation.

\section{ULTRASONIC METHODS}

Two methods for ultrasonic signal acquisition and processing are described: (1) the pulse-echo method and (2) the acousto-uitrasonic method. These two methods underly the discussion of material characterization concepts that follows. 


\section{Pulse-Echo Method}

A pulse-echo configuration is shown in figure 8 . Coupling a transducer (probe) to a material sample results in a series of ultrasonic echoes that can be analyzed either in the time or frequency domain, (fig. 9). A single probe serves as a sending and receiving transducer to excite and collect ultrasonic signals in a pulse-echo mode.

Time domain methods employ electrical analogs of ultrasonic echo waveforms that are displayed in figure 9 as signal amplitude (voltage) versus time. Specific signals, e.g., echoes B1 and B2, are selected for examination and the measurement of energy, velocity, or attenuation. Time domain measurements currently predominate for defect and material characterizations (Papadakis, 1976; Krautkramer and Krautkramer, 1977; Vary, 1980a).

Frequency domain methods begin with the acquisition and transformation of time domain signals, e.g., echoes $B 1$ and $B 2$ as in figure 9 . Transformations to the frequency domain are made by either (1) analog frequency spectrum analyses or (2) digital Fourier transform algorithms (Adler, et al. 1977; Bracewel1. 1978; Rose and Thomas, 1979; Vary, 1979b, 1980b; Fitting and Adler, 1981). Information concerning the material microstructure is obtained by deconvolving the waveforms of $B 1$ and $B 2$. The frequency domain approach, associated concepts, and some salient results will be discussed at length in this paper (under Microstructure Transfer Function Model and Experimental Verification).

\section{Acousto-U1trasonic Method}

It is instructive to contrast the acousto-uitrasonic method with the pulse-echo method. It is a generalized version of the pulse echo method and has attributes that make it practical for assessing mechanical properties of composite laminates and other highly heterogeneous, anisotropic structures (Vary, 1980b; 1982).

Apparatus for the acousto-ultrasonic method is 117 ustrated in figure 10. The configuration differs from that of the pulse-echo method in several important ways. Firstly, two probes are used; a sender and receiver. Secondly, the probes are coupled to the material in a manner that does not permit acquisition of a set of direct echoes as in figure 9. Thirdly, the received signals are considerably more complicated functions of boundary conditions, microstructure, etc., (Williams, et a1. 1982).

The object of the acousto-ultrasonic method is to generate elastic waves that will interact with material morphology and boundary surfaces in a manner similar to spontaneous stress waves that arise at the onset of microcrack nucleation, fracture, etc. As indicated in figure 10 the resultant output waveform resembles "burst' type acoustic emission (Liptai and Harris, 1971). The acousto-ultrasonic waveform carries information about the material through which it runs. It is a function of multimode velocities, attenuations, dispersions, multiple reflections, etc. It has been shown empirically (figs. 1 and 2), that the acousto-ultrasonic waveform will yield significant correlations with mechanical properties.

Analysis of acousto-ultrasonic signals is accomplished by measurement of a "stress wave factor" (SWF). The SWF may be measured in one of several ways 
to assign a numerical value to the acousto-ultrasonic waveform. For example, as in figure 10, the SWF may be evaluated as a "ringdown" oscillation count as that used in quantifying acoustic emission signais. Or, the SWF may be taken as the root-mean-square (RMS) voltage of the output waveform. In the frequency domain the SWF may be evaluated in terms of the power spectrum or spectral features that change with material factors (Vary and Bowles, 1979).

\section{CONCEPTUAL FOUNDATIONS}

Although significant empirical correlations among ultrasonic measurements and mechanical properties exist, they often appear fortuitous or accidental. The fundamental relations underlying many of these correlations are currently unknown. Some of the correlations are probably traceable to fundamental relations between velocity and elastic moduli while others are traceable to relations between attenuation and microstructure; e.g., grain size, shape; inclusions; second phase particles (Papadakis, 1965b; Serabian and Wtlliams, 1978; Goebbels, 1980; Serabian, 1980). After a discussion of empirical approaches, this section describes three conceptual models suitable for advancing the theoretical bases for ultrasonic materials assessment.

\section{Empirical Approaches}

Empirical correlations of ultrasonic quantities and various mechanical properties appear in figures 1 to 7 and 11 . The pulse-echo and acoustoultrasonic methods were used to produce these correlations. These empirical results generally lack established theoretical foundations. The data in figure 7 , for example, contradict the expectation that velocity varies inversely with density according to theoretically-based equations for the shear and longitudinal moduli (Green, 1973, Schreiber, et a1. 1973).

The empirical approach is epitomized by the "adaptive learning network" ( $A L N)$ method, ( $f i g .11)$. The $A L N$ method requires no fundamental understanding of interrelations between ultrasonic measurements and the mechanical properties evaluated. The method relies on collecting sufficient ultrasonic data (say, attenuation and velocity measurements at several frequencies) and applying multiple regression analysis procedures. The raw data is used to define a polynomial expression that gives the best combination of coefficients and exponents when fitted to corresponding measurements of a mechanical property. The polynomial is then used as the ultrasonic "predictor" of the mechanical property, e.g., shear strength in figure 11 (Williams and Zwicke, 1982). The ALN method works, but fundamental interrelations remain unspecified.

The previously-described acousto-ultrasonic method depends on simulating stress waves to assess mechanical properties. The results in figure 2 are based on combined acousto-ultrasonic and velocity measurements. Combining measurements and using the ALN approach an empirically-based expression was derived to correlate an acousto-ultrasonic "estimator" (predictor) with destructively measured interlaminar shear strengths in a set of composite laminates with a range in fiber fraction (Vary and Bowles, 1977).

The acousto-ultrasonic SWF (stress wave factor) can be taken as a relative measurement of the efficiency of stress wave energy transmission in the region 
between the sending and receiving probes (Vary, 1982). For example, in composite laminates the SWF can be interpreted as a quantification of the efficiency of dynamic strain energy transfer. In unidirectional composite laminates the SWF is greatest along the fiber direction which is also the direction of greatest strength (Vary and Lark, 1979).

Figure 6 demonstrates that the SWF decreases with increasing fatigue damage. This implies that fatigue damage will produce an increase in attenuation, as is apparent from figure 5. Indeed, a decrease in the SWF generally corresponds to increased ultrasonic attenuation. Figure 6 also provides evidence that the SWF is an indirect measure of how (degradation of) mechanical properties will affect the efficiency of stress wave propagation. This is an important point because it indicates a link between ultrasonic waves used to assess mechanical properties and the propagation of stress waves, such as those arising during mechanical fallure processes (plastic deformation, microcracking, fracture, etc.). This notion will be used later in discussing a stress wave interaction model.

\section{Conceptua 1 Mode1s}

To find interrelations that connect uitrasonic quantities with microstructure an mechanical properties it is necessary to go beyond current theory and postulate new bases for the experimentally observed relations. The empirical relations between ultrasonic measurements and fracture toughness of polycrystalline solids, as those in figures 3 and 4 , can serve as a starting point. Fracture toughness is a measure of a material's resistance to catastrophic crack propagation. The discussion that follows will deal with assessment of microstructural factors that govern crack nucleation events at the onset of fracture.

Spontaneous stress waves that arise during dislocation movements, microcrack nucleation, plastic deformation, and fracture are ultrasonic in nature. It is reasonable, therefore, to expect that ultrasonic probing can interrogate the microstructure to infer its effect on the stress waves that interact with it during the aforementioned processes, (fig. 12). Of course, the role of microstructure in controlling mechanical properties and behavior is well established (Macrone, 1977; Froes, et a1. 1978).

The idea illustrated in figure 12 can be implemented by treating microstructure as having a mathematically definable modulation transfer function that governs stress wave propagation. The analysis then proceeds by deconvolving output versus input signals (see Microstructure Transfer Function Model).

Three conceptual models are needed to establish a basis for interrelating ultrasonic, microstructural, and mechanical property factors: (1) stress wave interaction mode1, (2) microstructure transfer function mode1, and (3) microcrack nucleation mechanics mode1. The models, shown schematically in figures 13 to 15 , are needed to connect ultrasonically measured quantities to destructively measured mechanical properties, e.g., toughness, strength. 


\section{Stress Wave Interaction (SWI) Model}

Vary (1979a; 1980b) proposed a stress wave interaction (SWI) model in which spontaneous uitrasonic stress waves interact with material microstructural factors to the extent that they actually promote microcracking and also catastrophic crack extension. This agrees with dynamically-based models for fracture behavior (Kolsky, 1963, 1973; Curran, et a1. 1977; Fu, 1983a, 1983b).

The stress wave interaction (SWI) mode can be used to develop a theoretical basis for correlations found between ultrasonic attenuation and material strength and fracture toughness. The working hypothesis is that propagation of probe ultrasound is governed by the same factors that govern stress waves generated during fracture (although there is a tacit assumption that at the onset of fracture essentially linear elastic conditions prevail).

The SWI model invokes the concept that critical sites are activated by spontaneous stress waves emitted at the onset of catastrophic (rapid, unstable) crack growth. These sites are potential microcrack nucleation sites that can absorb or release stress wave energy. As indicated in figure 13, the SWI mode 1 assumes a critical wavelength commensurate with the dimensions of potential microcrack nucleation sites, e.g., precipitates, second phase particles, grains, etc. The SWI model also assumes that an avalanche (or cascading) effect occurs in which increasing numbers of crack nucleations sites are activate by the advancing stress wavefront. Moreover, the advancing stress wavefront is assumed to be reinforced as energy is released at the nucleation sites.

The mode of stress wave interaction with crack nucleation sites is given by an appropriate microcrack nucleation mechanics (MNM) model, described later. The MNM model must specify the ultrasonic stress wave energy transfer mechanism peculiar to a given microstructure. A material transfer function (MTF) model will be discussed first since it forms the bridge between the SWI and MNM models.

\section{Microstructure Transfer Function (MTF) Model}

Considering material microstructures as mechanical "filters" that have a transfer function definable in terms of ultrasonic attenuation coefficients proves to be a useful concept (Vary, 1980b). The conditions under which this microstructure transfer function (MTF) can be defined are restricted. A polycrystalline aggregate is assumed for the purposes of this discussion. It is also assumed that the sample has flat, parallel opposing surfaces and satisfies the conditions necessary to obtain two back surface echoes as shown in figures 9 and 14 . These constraints are desired for mathematical convenience as well as for ease of signal acquisition (Truell et al. 1969; Papadakis, 1976). Signal acquisition and processing is accomplished as described by Vary (1979b; 1980a; 1980b) and Generaz10 (1984).

It will be seen that frequency domain analysis yields an uitrasonic transfer function, $T$, for the material in terms of its attenuation and reflection coefficients. The quantities B1, B2, E1, E2, T, and $R$, in figure 14, are Fourier transforms of the corresponding time domain quantities (Bracewell, 1978). In the frequency domain, signal deconvolution and determination of the transfer function can proceed with simple mathematical manipulations. The 
attenuation coefficient, a function of frequency, is (Serabian and Williams, 1978; Serabian, 1980),

$$
\alpha=c f^{m}
$$

where, $f$ is uitrasonic frequency and $c$ and $m$ are constants that characterize the attenuation properties of the material probed. Equation (1) is a generalized form that in the context of this paper applies to attenuation due to scattering by microstructural features like grains, inclusions, and second phase particles.

A broadband ultrasonic pulse signal will produce a series of back surface echoes in the material specimen. The first two back echoes, B1 and B2, reenter the ultrasonic probe which acts as both a sender and receiver, (fig. 9). It is appropriate to take the internal echo El, (fig. 14), as the source for the "reduced" signal $B$ T, i.e., reduced by the factor $(1+R)$ where $R$ is the reflection coefficient at the specimen-transducer interface (True11, et al. 1969; Papadakis, 1976). The reflection coefficient is unity, 1 , at the free surface. Part of the energy of $E I$ is reflected and appears as the second internal echo E2 giving the reduced echo B2, thus,

$$
\begin{aligned}
B 1 & =(1+R) E 1 \\
B 2 & =T R(1+R) E T
\end{aligned}
$$

The quantity $T$ is the MTF and incorporates signal modulation factors associated with the microstructure (grain scattering, absorption, etc. Combining equations (2) and (3) yields.

$$
T=B 2 / R B 1
$$

Transfer functions associated with signal transduction and simflar factors can be ignored because in the pulse-echo configuration they vanish just as the term $(1+R)$ El vanishes in equation (4). Papadakis (1976) has demonstrated that the attenuation coefficient can be found by frequency spectrum analysis and that it may be written as,

$$
\alpha=(1 / 2 x) \ln (\mathrm{RB} 1 / \mathrm{B} 2)
$$

where, $x$ is the specimen thickness. Since both the MTF and the attenuation coefficient are defined in terms of $B 1$ and B2 which are Fourier transforms of the corresponding time domain signals, equations (4) and (5) can be combined to get,

$$
T=\exp (-2 \times \alpha)
$$

Hence, the MTF is definable as a function of the (frequency dependent) attenuation coefficient of the microstructure (Vary, 1980b). Equation (6) forms the basis for ultrasonic determination of mechanical properties (1ike toughness) that depend on microstructure. But, it is first necessary to establish which microstructural factors govern toughness and to relate these factors to the MTF. 


\section{Microcrack Nucleation Mechanics (MNM) Model}

The microcrack nucleation mechanics (MNM) model was proposed by vary (1979a) and elaborated upon by Fu $(1982$; 1983a; 1983b). The MNM mode 1 is based on the stress wave interaction (SWI) model. The MNM model is used to derive a relation connecting the MTF (and hence, the attenuation properties of a microstructure) with the microcrack nucleation sites activated during the onset of catastrophic crack growth. The MNM model described here pertains specifically to plane strain fracture toughness and the microstructural factors that govern plane strain fracture toughness (Brown and Srawley, 1966; Hahn, et al. 1972; Froes, et a1. 1978). The MNM model assumes that stress wave interactions promote microcrack nucleation in accordance with the SWI model.

The MNM model is depicted in figure 15. A stress wavefront is shown traveling from grain $S$ to $R$. These "grains" represent critical, interacting microstructural features such that, when grain $S$ releases energy by fracturing, grain $R$ will absorb some of this energy (carried by the stress wave). Given an existing static stress field around $R$, it is only necessary for the impinging stress wave to impart enough energy to take $R$ above a fracture threshold. The energy imparted to $R$ depends on the ultrasonic (stress wave) attenuating properties of the microstructure in the ligament between grains $S$ and $R$. The important point is that this MNM model links all the previously discussed SWI and MNM factors.

Using the MNM model depicted in figure 15 Vary (1979a) derived an expression interrelating ultrasonic factors, material microstructure, and fracture toughness (and yield strength),

$$
\left(K_{I c} / \sigma_{y}\right)^{2}=M\left(v_{\ell} \beta_{\delta} / m\right)^{1 / 2}
$$

The right side of equation. (7) consists of ultrasonically determined quantities, where $v_{Q}$ is velocity, $m$ is the exponent on frequency in equation (1), and $M$ is an experimental constant for the material being evaluated, while,

$$
\beta_{\delta}=d \alpha / d f
$$

The derivative in equation ( 8$)$ is that of the attenuation coefficient evaluated at a frequency that corresponds to the critical ultrasonic wavelength in the material. This wavelength is defined by the critical dimension, $\delta$ (e.g., mean grain size) in the microstructure. This dimension is taken as common to all microcrack nucleation sites that interact with the stress waves in accordance with the SWI model. This critical dimension is the link that establishes how the material transfer function, $T$, may be evaluated relative to specific nucleation sites. For, by specifying the critical dimension (or critical microstructural feature) one can estimate stress wave energies (Vary, 1979a).

The left side of equation (7) consists of the square of the ratio of plane strain fracture toughness to yield strength. The square of this ratio is called a "characteristic length." . This characteristic length quantity is also a measure of the fracture toughness (Hahn et al. 1972). It is proportional to the size of the plastic (or process) zone that develops at the crack front at the onset of unstable crack growth. The characteristic length is a measure of an extrinsic property of the microstructure that ranks its toughness. That is, 
tougher materials exhibit larger plastic zones and, hence, more crack blunting will occur. Therefore, equation (7) uniquely relates factors that govern toughness with ultrasonic propagation properties of the microstructure.

The quantities in parentheses on both sides of equation (7) are functions of material microstructure. Although the parameter $M$ remains constant for a given alloy, the characteristic length and ultrasonic quantities change with heat treatment, phase composition, and other factors that affect toughness or strength.

\section{EXPERIMENTAL VERIFICATION}

The correlation predicted by equation (7) has been experimentally verified (Vary, 1978b) and figure 16 shows the predicted correlation for three metal alloys. In these metals the critical microstructural dimension is the average grain size. It can be inferred from figure 16 that the size of the plastic (or crack blunting) zone, i.e., "characteristic length," depends on ultrasonic attenuation properties of the material.

Apparent1y, metal mirocstructures that are more attenuating develop larger plastic zones. But, tougher metals are those that can accommodate stress wave interactions by absorbing more stress wave energy in localized plastic deformation zones (via dislocation motions). This should be contrasted with findings for fiber reinforced composites. In composites less attenuation appears to correspond to greater toughness (Vary and Bowles, 1977; Vary and Lark, 1979). Since composites generally have brittle matrices that usually cannot sustain plastic deformation, it is better to have prompt, efficient dissipation of stress wave energy away from microcrack nucleation sites, i.e., lower attenuation.

By examining figure 3 , one might infer that decreasing grain size corresponds to increasing toughness. Figure 4 fllustrates the opposite, where increasing grain (tungsten carbide crystal) size corresponds to increasing toughness. Clearly, there is more to consider than grain size (or even grain shape) relative to assessing factors that govern toughness. Vary and Hull (1982; 1983) have shown that critical microstructural features governing toughness in metals are those that support dislocation motions. This is apparent from figure 4 where the cobalt "cement" (between the carbide crystals) with its high dislocation density appears to govern fracture toughness.

In the case of the titanium alloy depicted in figure 17 , there are three levels of microstructure: grains, colonies, and alternating alpha/beta phase platelets. The question is which of these features exerts the greatest influence on fracture toughness. This question has been answered on the basis of the previously described models (Vary and Hul1, 1982). The results shown in figure 18 indicate that the best empirical correlation and also the best agreement with theory, i.e., with equation (7), occur with data based on the beta phase thickness. The alpha phase thickness was found to be somewhat less significant than the beta phase thickness, i.e., correlation coefficients were 0.977 , and 0.998 , respectively. The colony size was weak ly influential, while grain size influence was indeterminate.

Vary and Hull (1982) concluded that in the titanium alloy studied, that both the alpha and beta phases are critical microstructural features. This 
conclusion was supported by fractographic studies that identify the alpha phase aspect ratio as a critical factor (Froes et a1. 1978). However, the best correlation coefficient is obtained with the beta phase, (fig. 18). Hence, from the ultrasonic viewpoint the beta phase has the greatest influence on toughness. This is apparently due to its high dislocation density (plasticity) and concomitantly greater attenuation (i.e., high absorption of stress wave energy).

\section{SUMMARY}

The first two of the five sections that comprise the main body of this paper give a selective review of ultrasonic NDE for assessment of mechanical properties and microstructure. Examination of the literature shows a lack in theoretical foundations for ultrasonic prediction of mechanical properties of engineering solids. There are abundant correlations among ultrasonic quantities, mechanical properties, and microstructural factors that can be cited; however, they are usually empirically based and often appear fortuitous or accidental.

The third section contrasts two ultrasonic methods that have proven useful for ultrasonic evaluation of mechanical properties: the pulse-echo and acousto-ultrasonic methods. Signal acquisition and analysis techniques are described and examples are given on how the two ultrasonic measurement methods have helped further the understanding of microstructural and morphological factors governing mechanical properties.

The fourth section describes some conceptual foundations for ultrasonic measurement of mechanical properties and critical microstructural factors that govern mechanical properties. Three conceptual models are described: (1) the stress wave interaction mode1, (2) the mircostructure transfer function mode1, and (3) the microcrack nucleation mechanics model.

The fifth section gives an illustrative example showing how the three models can be combined to predict correlations between ultrasonic attenuation factors and fracture toughness. The fracture toughness example demonstrates subtie interrelations between ultrasonic stress waves and critical microstructural features, in addition to providing experimental verification of the predicted correlations. It is also apparent that ultrasonic examination can help improve understanding of microstructural factors that govern mechanical properties.

\section{CONCLUSION}

This paper has reviewed recent literature, described some new concepts, and presented experimental results concerning ultrasonic materials characterization. For illustrative purposes, emphasis was placed on ultrasonic assessment of fracture toughness. There are, however, ramifications that extend beyond the current primarily empirically-based assessment of toughness and other mechanical properties. Two important ramifications are that: (1) the current theoretical foundations for the ultrasonic assessment of mechanical properties are inadequate and require reexamination and (2) the use of ultrasonic NDE techniques can aid in understanding factors that govern mechanical properties of engineering solids. It was shown that the conceptual models 
described herein can: (1) help improve theoretical foundations for ultrasonic assessment of mechanical properties and (2) help identify factors that govern mechanical properties.

\section{REFERENCES}

1. Adler, L., Cook, K.V., and Simpson, W.A.' (1977) in "Research Techniques in Nondestructive Testing," vol. 3 (R.S. Sharpe, ed.), pp. 1-49. Academic Press, London, England.

2. Alers, G.A., Flynn, P.L., and Buckley, M.J. (1977), Mater. Eva1. 35:4, 77-84.

3. Bracewel1, R.N. (1978), "The Fourier Transform and Its Applications," McGraw-Hi11, New York, New York.

4. Brown, A.F. (1973), U1trasonics, 11, 202-210.

5. Brown, W.F., Jr., and Srawley, J.E. (1966), "Plane Strain Crack Toughness Testing of High Strength Metalic Materials," ASTM STP 410, American Society for Testing and Materials, Philadelphia, Pennsylvania.

6. Curran, D.R., Seaman, L., and Shockey, D.A. (1977), Phys. Today 30:1, $202-210$.

7. Duke, J.C., Jr., Henneke, E.G., Stinchcomb, W.W., and Reifsnider, K.L. (1983) in "Proceedings of the 2nd International Conference on Composite Structures," (I.H. Marshal1, ed.) pp. 53-60. Applied Science Publishers, London, England.

8. Evans, A.G., Tittmann, B.R., Ahlberg, L., Khuri-Yakub, B.T., and Kino, G.S. (1978), J. App 1. Phys. 49:5, 2669-2679.

9. Fitting, D.W., and Adler, L. (1981), "Ultrasonic Spectral Analysis for Nondestructive Evaluation," Plenum Press, New York, New York.

10. Flynn, P.L. (1977), "Cohesive Strength Prediction of Adhesive Joints," AFML TR-77-44, pp. 59-65. Air Force Materials Laboratory Dayton, Ohio.

11. Froes, F.H., Chesnutt, J.C., Rhodes, C.G., and Williams, J.C. (1978) in "Toughness and Fracture Behavior of Titanium," (R.G. Broadwe 11 and C.F. Hickey, Jr. eds.), ASTM STP 651, pp. 115-153. American Society for Testing and Materials, Philadelphia, Pennsylvania.

12. Fu, L.S. (1982), Applied Mechanics Review 35:8, 1047-1057.

13. Fu, L.S. (1983a), Engineering Fracture Mechanics, International 18:1, 59-67.

14. Fu, L.S. (1983b) in "Developments in Mechanics," vol. 12 (E.J. Haug and K. Rim, eds.) pp. 263-265. University of Iowa Press, Iowa City, Iowa. 
15. Generazio, E.R. (1984), "The Role of the Reflection Coefficient in Precision Measurement of U1trasonic Attenuation," TM-83788 National Aeronautics and Space Administration, Washington, DC.

16. Gericke, 0.R. (1970) in "Research Techniques in Nondestructive Testing," vol. 1 (R.S. Sharpe, ed.), pp. 31-61. Academic Press, London, England.

17. Goebbe1s, K. (1980) in "Research Techniques in Nondestructive Testing," vol. 4 (R.S. Sharpe, ed.), pp: 87-157. Academic Press, London, England.

18. Green, R.E., Jr. (1973a), "Ultrasonic Investigation of Mechanical Properties, Treatise on Materials Science and Technology," vol. 3. Academic Press, New York.

19. Green, R.E., Jr. (1973b) in "U1trasonic International 1973," pp. 187-193. IPC Science and Technology Press, Ltd. Guilford, Surrey, England.

20. Hahn, G.T., Kanninen, M.F., and Rosenfield, A.R. (1972) in "Annual Reviews of Materials Science," vol. 2 (R.A. Huggins, ed.), pp. 381-404. Annual Reviews, Inc., Palo Alto, California.

21. Hayward, G.P. (1978), "Introduction to Nondestructive Testing, "American Society for Quality Control, Milwaukee, Wisconsin.

22. Henneke, E.G. II, Duke, J.C., Jr., Stinchcomb, W.W., Govada, A., and Lemascon (1983), "A Study of the Stress Wave Factor Technique for the Characterization of Composite Materials," CR-3670, NASA, Washington DC.

23. Jones, B.R. and Stone, D.E.W. (1976), Nondestruc. Test. 9, 71-79.

24. Juva, A. and Haarvisto, M. (1977), Brit. J. Nondestruc. Test. 19, 293-297.

25. Kaelble, D.H. and Dynes, P.J. (1977a) in "Composite Materials: Testing and Design," ASTM STP 617, pp. 190-200. American Society for Testing and Materials, Philadelphia, Pennsylvania.

26. Kaelble, D.H. and Dynes, P.J. (1977b), Mater. Eva1. 35, 103-108.

27. Kessler, L.W. (1974) in "1974 IEEE U1trasonics Symposium," pp. 735-737. Institute of Electrical and Electronics Engineers, New York, New York.

28. Klima, S.J., Watson, G.K., Herbe11, T.P., and Moore, T.J. (1981), "U1trasonic Velocity for Estimating Density of Structural Ceramics," TM-82765, NASA, Washington, DC.

29. Klinman, R., Webster, G.R., Marsh, F.J., and Stephenson, E.T. (1980), Mat1. Eval. 38:10, 26-32.

30. Kolsky, H. (1963), "Stress Waves in Solids," Dover Publishers, New York, New York. 
31. Kolsky, H. (1973) in "International Conference on Dynamic Crack Propagation," (G.G. Sih, ed.), pp. 399-414. Noordhoff International Publishing Co., Leyden, The Netherlands.

32. Krautkramer, J., and Krautkramer, H (1977), "UTtrasonic Testing of Materials," Springer-Verlag, New York, New York.

33. Kreher, W., Ranachowski, J., and Rejmund, F. (1977), U1trasonics 15, $70-74$.

34. Ledbetter, H.M. (1981), J. Appl. Phys. 52:3, 1587-1589.

35. Ledbetter, H.M., Fredrick, N.V., and Austin, M.W. (1980), J. App1. Phys. $51: 1,305-309$.

36. Liptai, R.G., Harris, D.0., Engle, R.D., and Tatro, C.A. (1971), Int. J. Nondestruc. Test. 3, 215-275.

37. Lloyd, E.A. (1974), Nondestruc. Test. 7, 331-334.

38. Lockyer, G.E., and Proudfoot, E.A. (1967), Amer. Ceram., Soc., Bu11. 46, $521-526$.

39. Macrone, R.K., ed. (1977) in "Treatise on Materials Science and Technology," vol. 11. Academic Press, New York, New York.

40. Martin, B.G., and Tsang, S. (1970), "The Early Detection of Fatigue Damage," AFML TR-70-124, Air Force Materials Laboratory, Dayton, Ohio.

41. Martin, B.G. (1977), J. App 1. Phys. 48, 3368-3373.

42. Mason, W.P. (1958) in "Physical Acoustics and the Properties of Solids," D. Van Nostrand Co., Princeton, New Jersey.

43. McMaster, R.C., ed. (1959), "Nondestructive Testing Handbook," Ronald Press Co., New York, New York.

44.. Meron, M., Bar-Cohen, Y., and Ishai, 0. (1977) J. Test. Eva1. 5, 394-396.

45. Murray, R.M. (1969), J. Res., Steel Casting Research and Trade Association, Sheffield, England, No. 5, pp. 31-43.

46. Papadakis, E.P. (1964a), J. App 1. Phys. 35, 1474-1482.

47. Papadakis, E.P. (1964b), J. App1. Phys, 35, 1586-1594.

48. Papadakis, E.P. (1965a), J. Acoust. Soc. 37, 703-710.

49. Papadakis, E.P. (1965b), J. Acoust, Soc. 37, 711-717.

50. Papadakis, E.P. (1970), Meta11. Trans. 1, 1053-1057.

51. Papadakis, E.P. (1976), in "Physical Acoustics-Principles and Methods," vol. 12 (W.P. Mason and R.N. Thurston, eds.), pp. 277-374, Academic Press, New York, New York. 
52. Papadakis, E.P. (1981), J. Acoust, Soc. Am. 7:3, 782-787.

53. Proudfoot, E.A. (1970), in "Advanced Technology for Production of Aerospace Engines," AGARD Conference Proceedings No. 64-70, pp. 17.0-17.15. Advisory Group for Aerospace Research and Development, Paris, France.

54. Rasmussen, J.G. (1962), Nondestruc. Test. 20, 103-110.

55. Rose, J.L. and Thomas, G.H. (1979), Brit. J. of Nondestruc. Test. 21:3, $135-140$.

56. Schlengermann, U. (1974), Z. Werkstofftec. 5, 242-248. H. Bruchter Technical Translations, Attadena, California, HB No. 9399 (1976).

57. Schlieke1mann, E.J. (1973), Nondestruc. Test. 5, 144-153.

58. Schreiber, E., Anderson, 0.L., and Soga, N. (1973), "Elastic Constants and Their Measurement," McGraw-Hill, New York, New York.

59. Schultz, A.W. (1971), SAMPE Q, 2, 31-37.

60. Serabian, S., and Williams, R.S. (1978), Mat1. Eva1. 36:8, 55-62.

61. Serabian, S. (1980), Brit. J. of Nondestruc. Test. 22:2, 69-77.

62. Smith, R.E. (1972), J. App 1. Phys. 43, 2555-2561.

63. Stone, D.E.W. (1978), Brit. J. Nondestruc. Test. 20, 65-75.

64. Stone, D.E.W. and Clarke, B. (1975), Nondestruc. Test. 8, 137-145.

65. Szilard, J. and Scruton, G. (1974) in "1974 U1trasonic Symposium Proceedings," pp. 707-710. Institute of Electrical and Electronics Engineers, New York, New York.

66. Thomas, R.L., Pouch, Y.H., Favro, L.D., Kuo, P.K., and Rosencwaig, A. (1980), J. App 1. Phys. 51:2, 1152-1156.

67. True11, R., Elbaum, C., and Chick, B.B. (1969), "U1trasonic Methods in Solid State Physics," Academic Press, New York, New York.

68. Vary, A. (1973), "Nondestructive Evaluation Technique Guide," SP-3097, NASA, Washington, DC.

69. Vary, A. (1978a), "Quantitative U1trasonic Evaluation of Mechanical Properties of Engineering Materials," TM-78905, National Aeronautics and Space Administration, Washington, DC.

70. Vary, A. (1978b), Mat1. Eval. 36:7, 55-64.

71. Vary, A. (1979a) in "Fracture Mechanics," (C.W. Smith, ed), ASTM STP 677, pp. 563-578 American Society for Testing and Materials, Philadelphia, Pennsylvania. 
72. Vary, A. (1979b) in Proceedings of the Twelfth Symposium on Nondestructive Evaluation," pp. 33-46. American Society for Nondestructive Testing, Columbus, Ohio and Southwest Research Institute, San Antonio, Texas.

73. Vary, A. (1980a) in "Research Techniques in Nondestructive Testing, " vol. 4. (R.S. Sharpe, ed.), pp. 159-204. Academic Press, London, England.

74. Vary, A. (1980b) in "Mechanics of Nondestructive Testing," (W.W. Stinchcomb, ed.), pp. 123-141. Plenum Publishing Co., New York, New York.

75. Vary, A. (1982), Mat1. Eva1. 40:6, 650-654, 662.

76. Vary, A. (1982), "Advanced Materials Technology," CP-2251, pp. 411-412, NASA, Washington, DC.

77. Vary, A., and Bowles, K.J. (1977), in "Proceedings of the Eleventh Symposium on Nondestructive Evaluation," pp. 242-258. American Society for Nondestructive Testing, Columbus, Ohio and Southwest Research Institute, San Antonio, Texas.

78. Vary, A., and Bowles, K.J. (1979), Polymer Eng. and Sc1, 19, 373-376.

79. Vary, A., and Hu11, D.R. (1982), Mat1. Eva1. 41:3, 309-314.

80. Vary, A., and Hu11, D.R. (1983), "U1trasonic Ranking of Toughness of Tungsten Carbide," TM-83358, NASA, Washington, DC.

81. Vary, A., and Lark, R.F. (1979), J. of Test. and Eva1. 7, 185-191.

82. Williams, J.H., Jr., and Do11, B. (1980), Mat1. Eva1. 38:5, 33-37.

83. Williams, J.H., Jr., Karagulle, H., and Lee, S.S. (1982), Mat1. Eval. $40: 6,655-662$.

84. Williams, J.H., Jr., Yuce, H., and Lee, S.S. (1982), Mat1. Eval. 16:5, $560-565$.

85. Williams, R.S. and Zwicke, P.E. (1982), Mat1. Eva1. 40:3, 312-317.

86. Wong, Y.H., Thomas, R.L., and Hawkins, G.F. (1978), Appl. Phys. Lett. $32: 9,539$.

87. Zurbrick, J.R. (1973), J. Test. Eva1. 1, 13-23. 


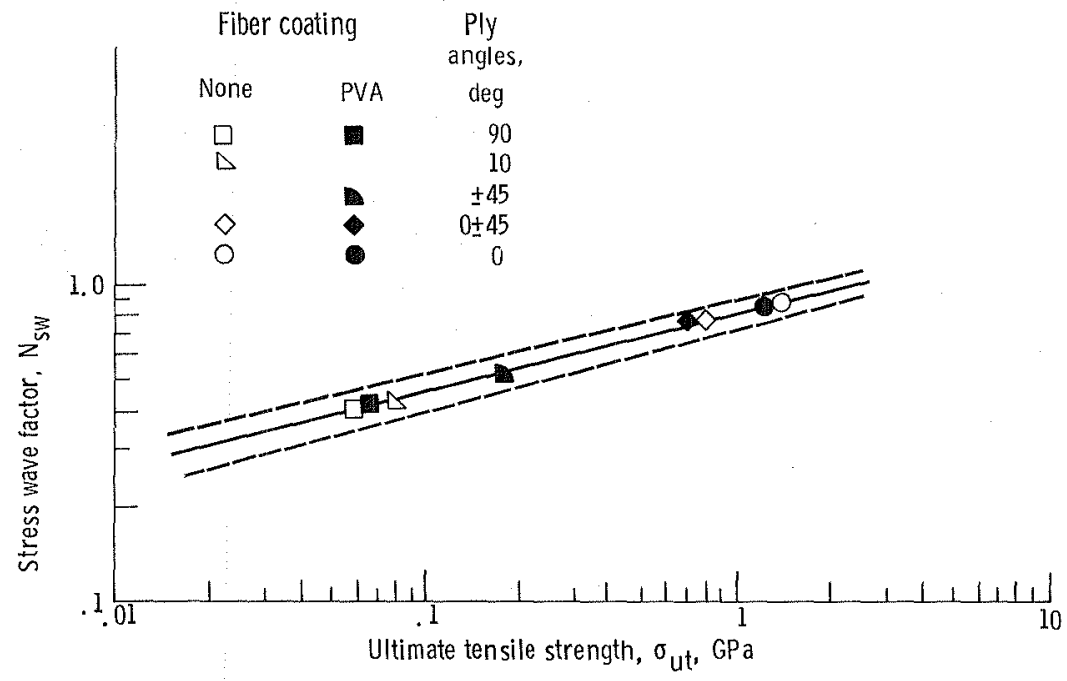

Figure 1. - Acousto-ultrasonic stress wave factor as co-function of tensile strength and ply angle in graphitelepoxy fiber composite laminates (Vary and Lark, 1979).

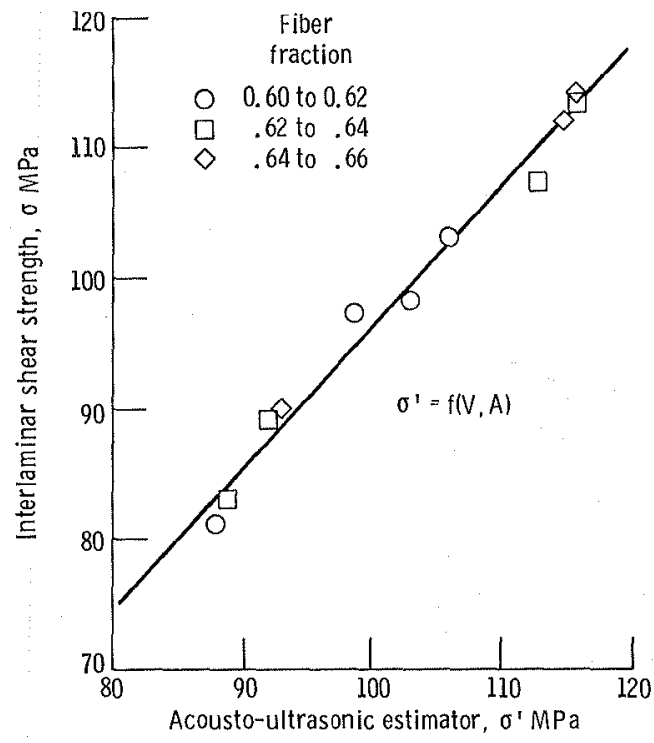

Figure 2. - Correlation of interlaminar shear strength with the acousto-ultrasonic estimator for graphite/polyimide fiber composite laminates (Vary and Bowles, 1977). 


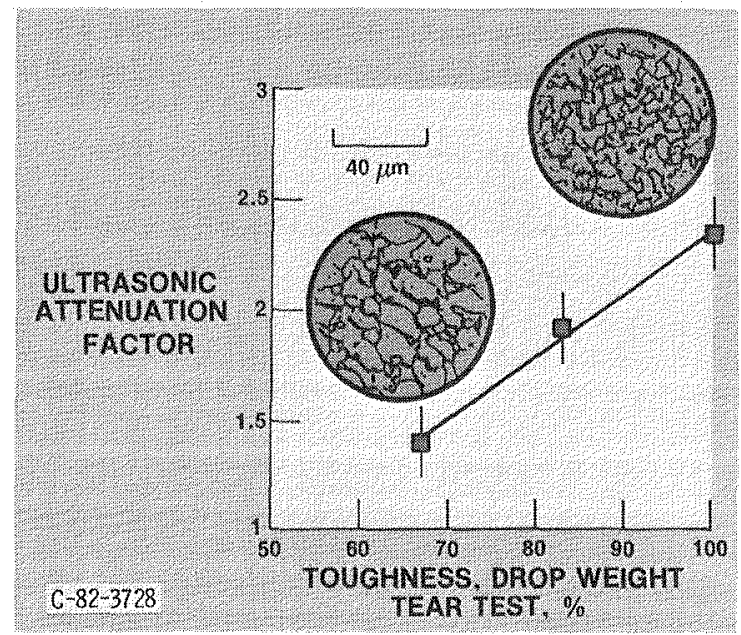

EACH DATA POINT REPRESENTS A DIFFERENT HEAT OF STEEL.

THE BARS INDICATE THE SCATTER ASSOCIATED SCATTER ASSOCIATED MEASUREMENT.

PHOTOMICROGRAPHS SHOW THAT GRAIN SIZE DECREASES WITH INCREASED TOUGHNESS
AND ATTENUATION.

Figure 3. - Ultrasonic attenuation factor as function of toughness as measured by drop weight test for low carbon steel (Vary, 1982).

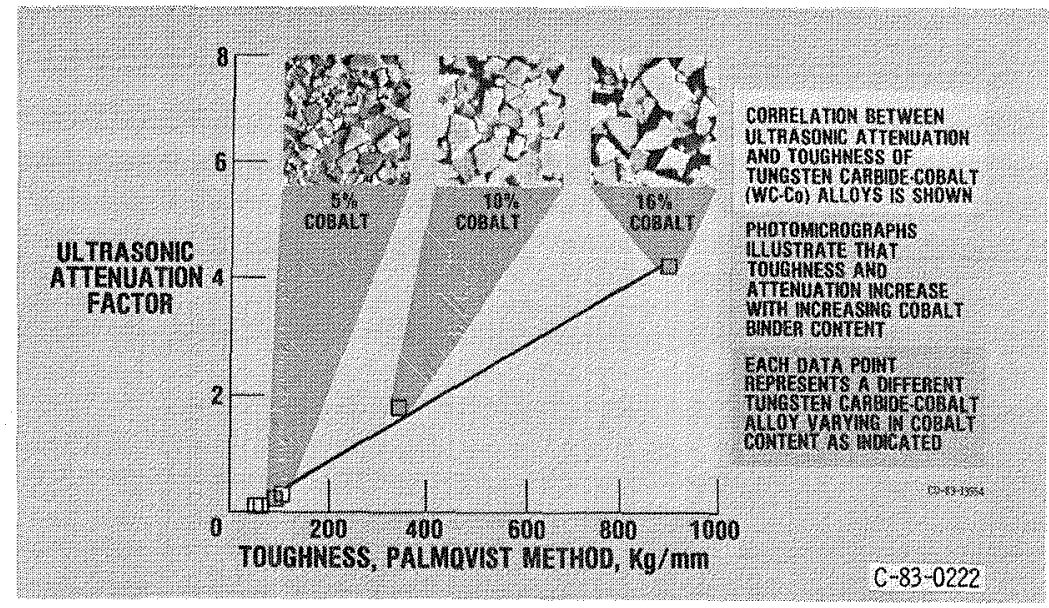

Figure 4. - Ultrasonic attenuation factor as function of toughiness as measured by Palmqvist method for cobalt cemented tungsten carbide (Vary and Hull, 1983). 

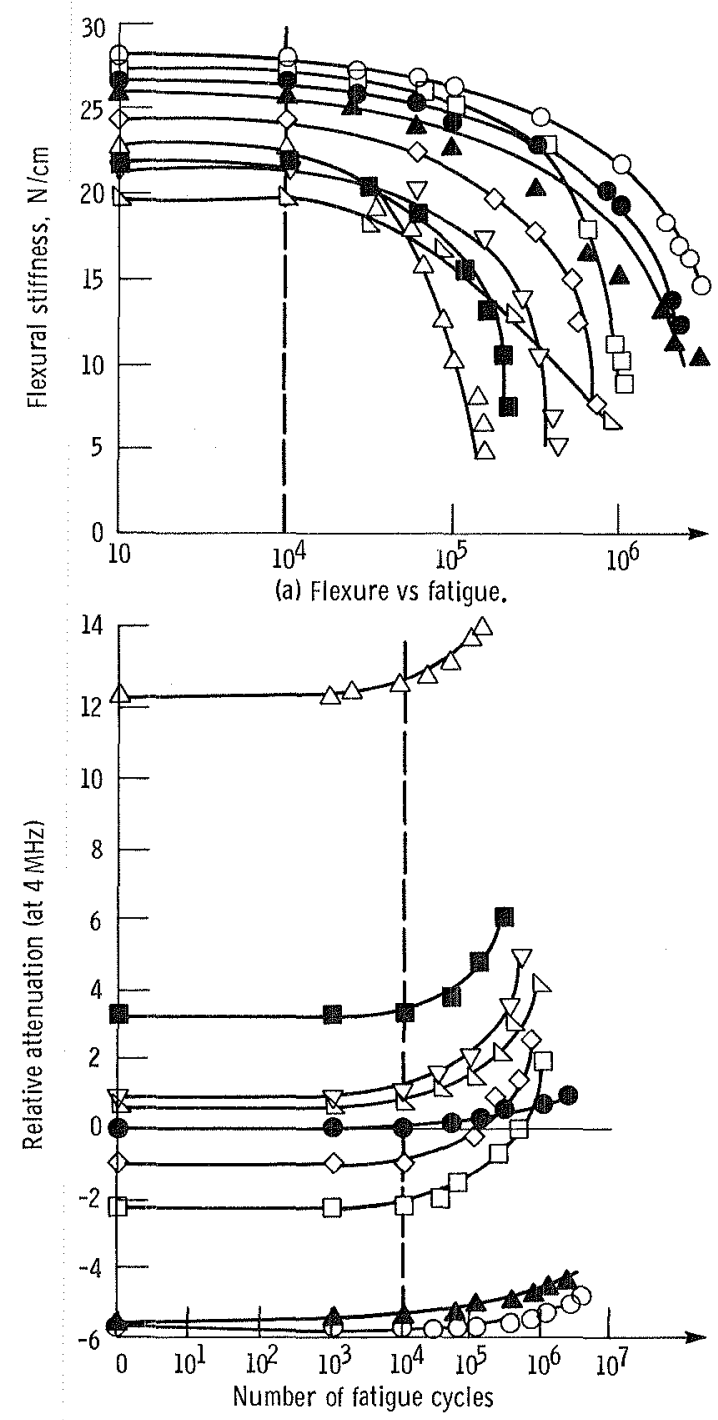

(b) Attenuation vs fatigue.

Figure 5. - Correlations of flexural stiffness and uttrasonic attenuation with fatigue in graphite / epoxy composite laminates (Williams, et al, 1982).

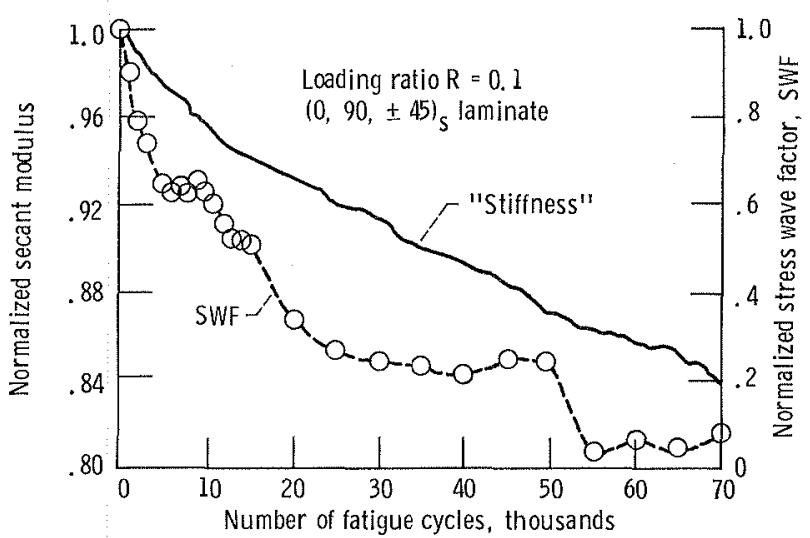

Figure 6. - Covariation of stress wave factor and longitudinal secant modulus with fatigue damage in graphite / epoxy fiber composite laminate (Duke, et al, 1983). 


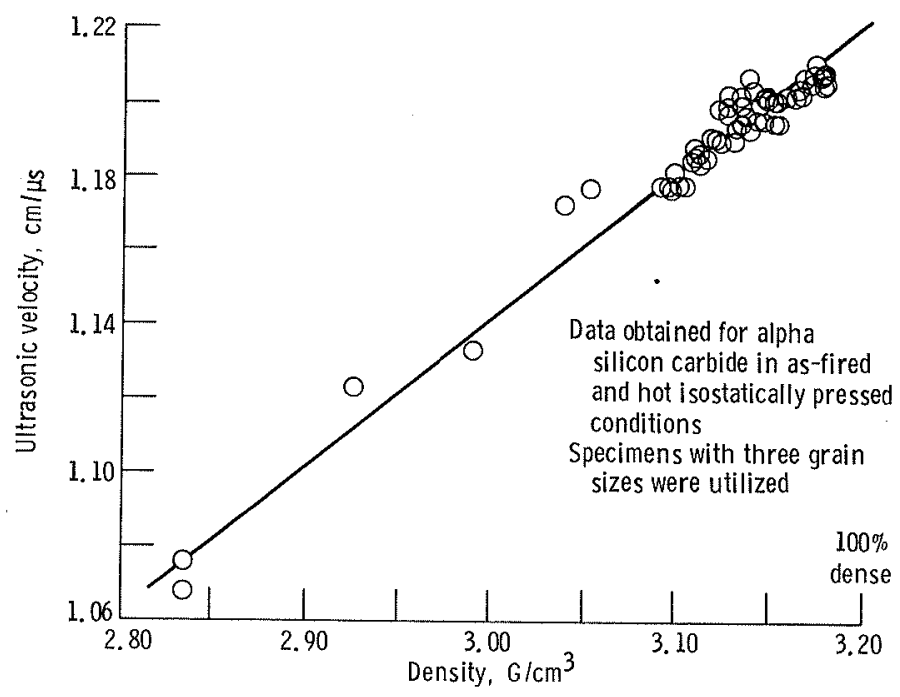

Figure 7. - Ultrasonic velocity as a function of bulk density for alpha silicon carbides (Klima, et al, 1981).

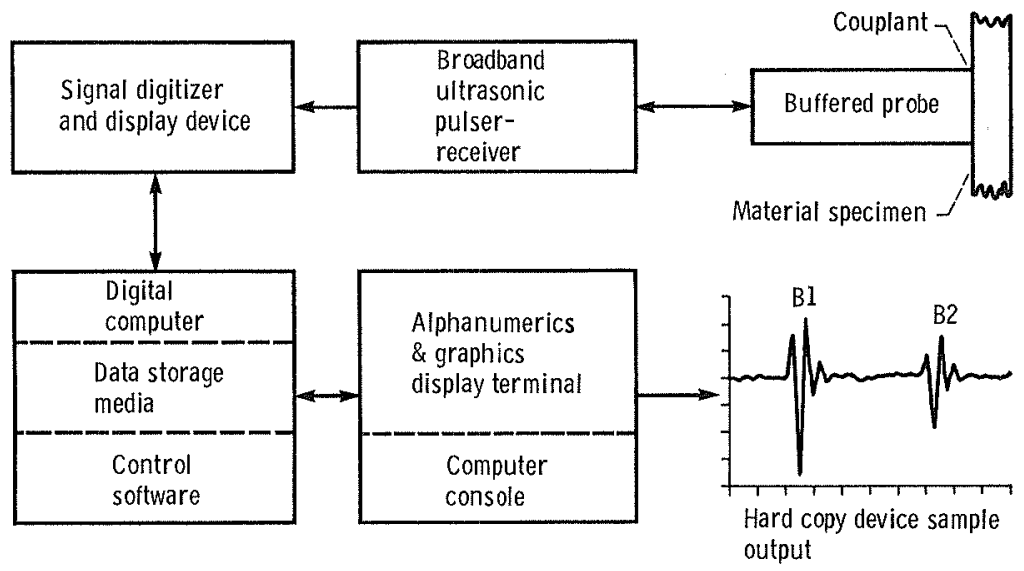

Figure 8. - Block diagram of computer system for ultrasonic signal acquisition and processing for pulse-echo velocity and attenuation measurements. 


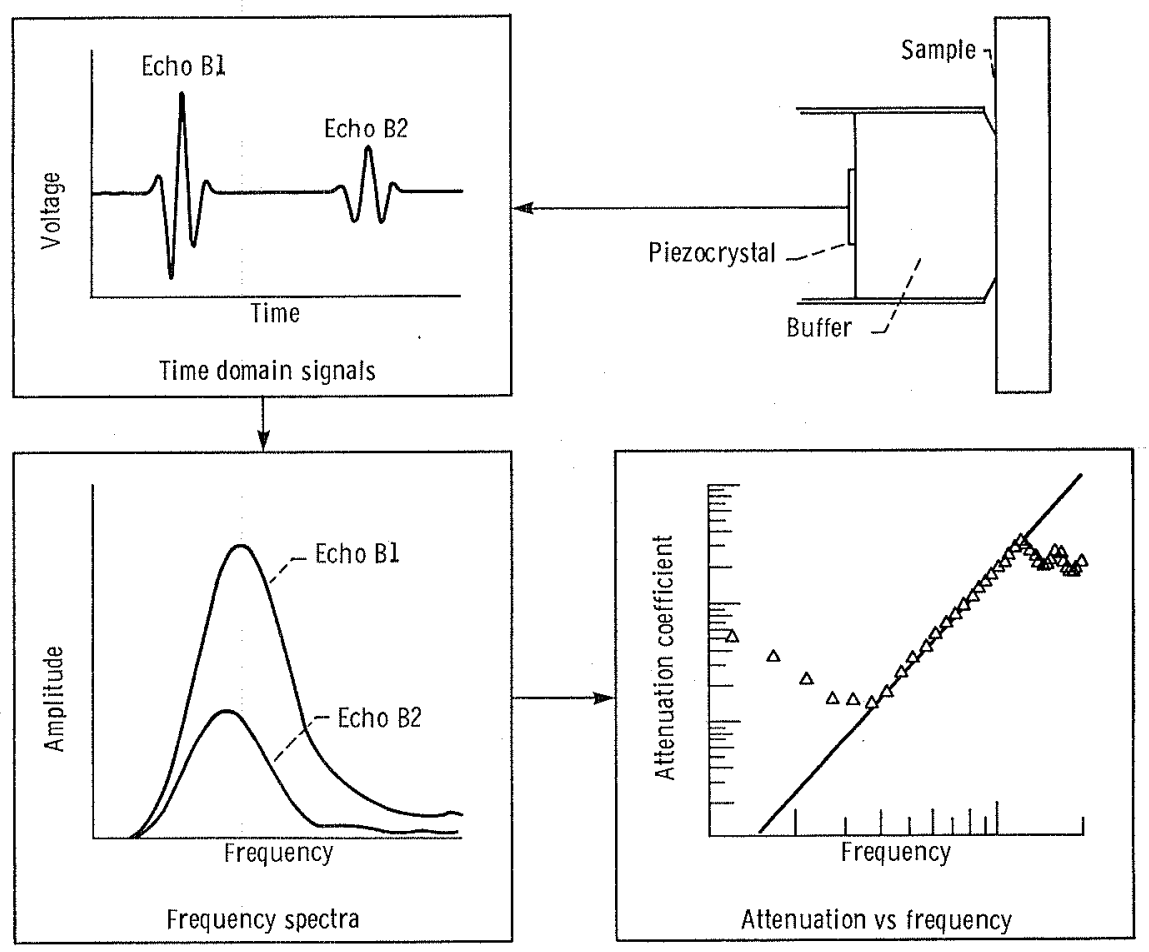

Figure 9. - Illustration of ultrasonic signal processing procedure for attenuation measurements using pulse-echo method.

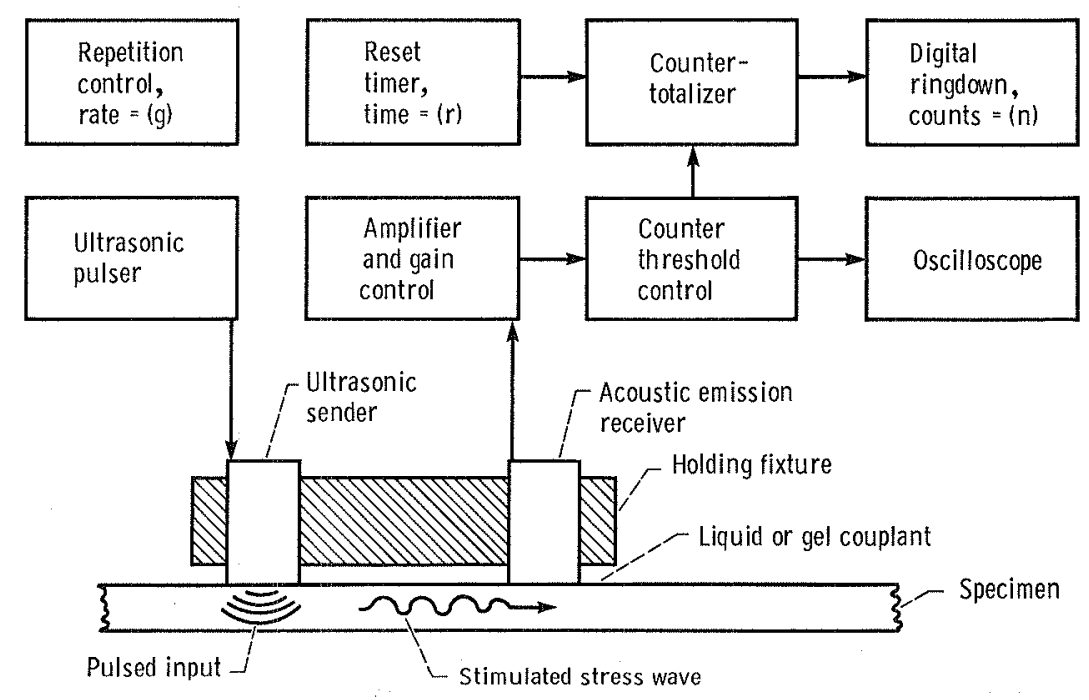

(a) Diagram of acousto-ultrasonic method used to measure stress wave factor (SWF), where SWF = grn.

Figure 10. - Typical apparatus and signals in acousto-ultrasonic stress wave factor measurement of material properties. 


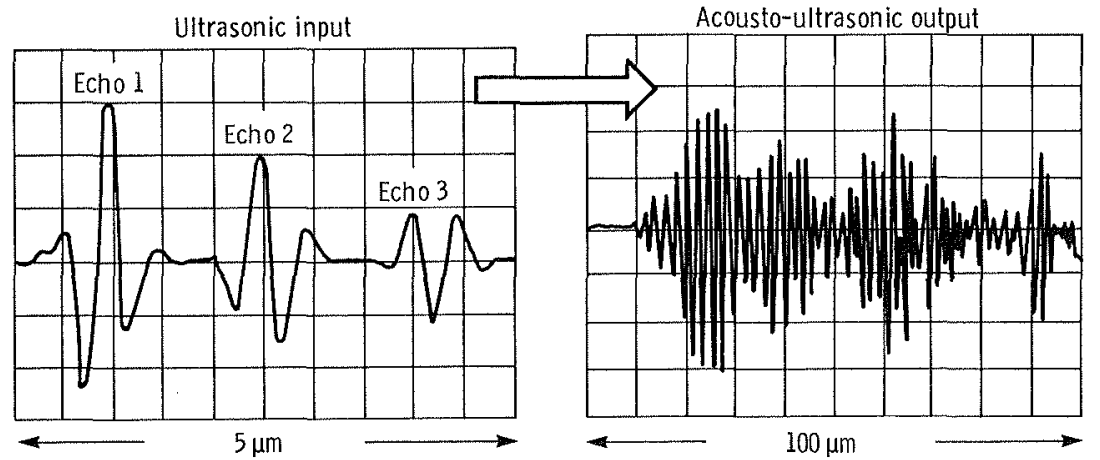

(b) Ultrasonic input and acousto-ultrasonic output signals showing complex modulation by material factors.

Figure 10. - Concluded.

$S V=$ Shear wave velocity

IV = Longitudinal wave velocity

A2 $\approx$ Attenuation at $2 \mathrm{MHz}$

$A 5=$ Attenuation at $5 \mathrm{MHz}$

A9 = Attenuation at $9 \mathrm{MHz}$
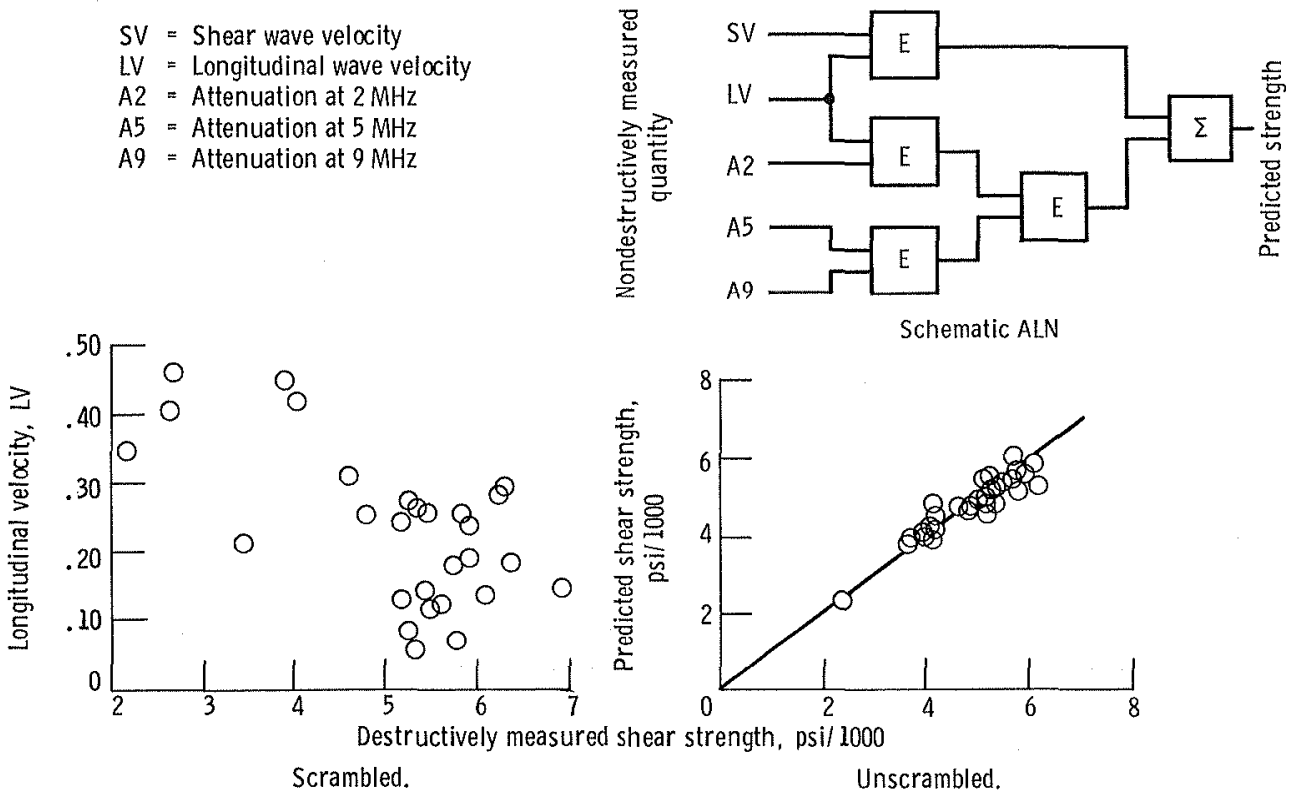

Figure 11. - Diagram illustrating adaptive learning network (ALN) and results predicting composite shear strength, where several measured quantities are "unscrambled" via ALN. 


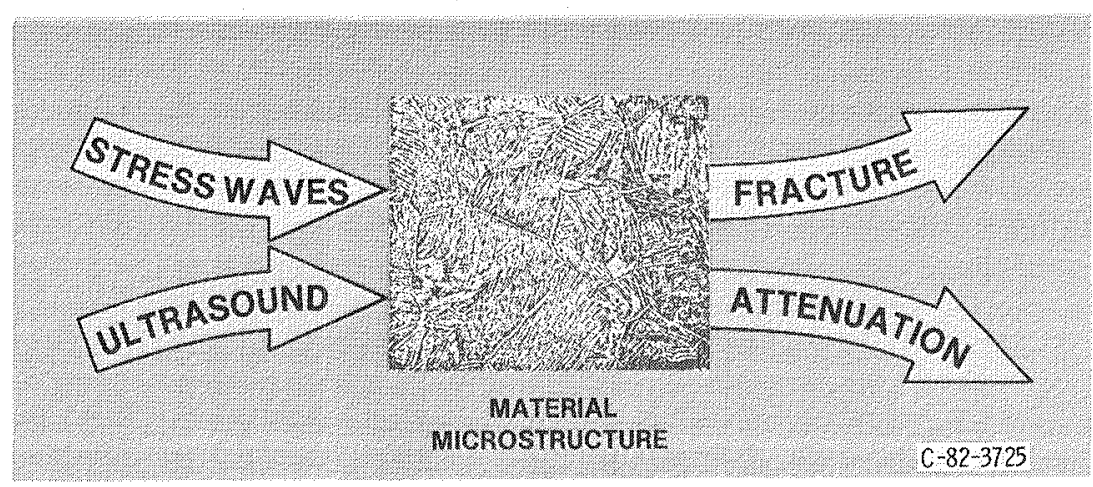

Figure 12. - Diagram of concept wherein ultrasonic attenuation measures microstructural factors that govern stress wave propagation during microfailure events.

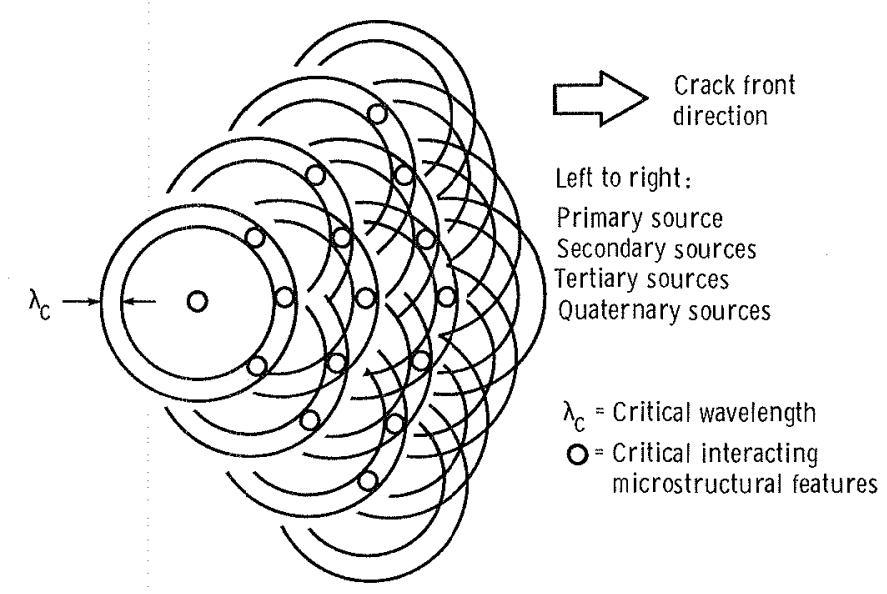

Figure 13. - Diagram illustrating stress wave interaction (SWI) model showing cascade effect during interactions with critical microstructural features. 


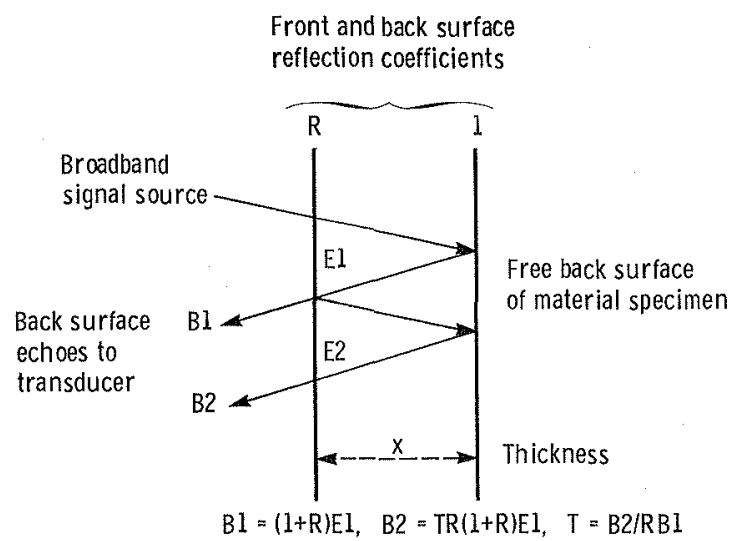

Figure 14. - Diagram of echo system for defining the microstructure transfer function (MTF), where T is MTF.

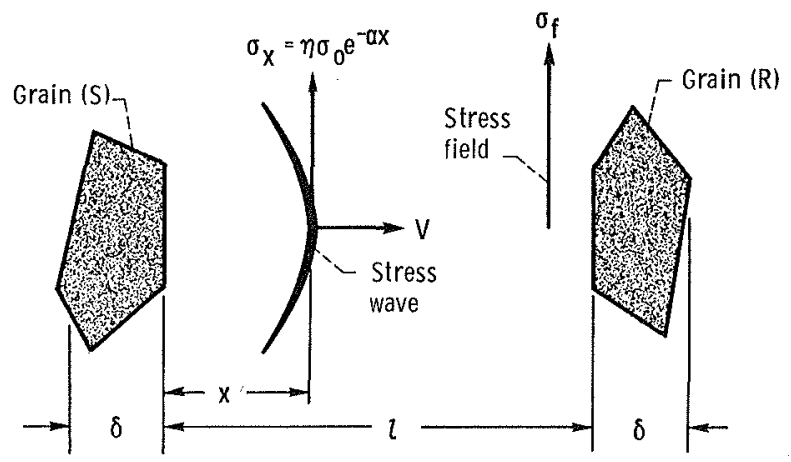

Figure 15. - Diagram of microcrack nucleation mechanics (MNM) model wherein crack nucleation in grain $\mathrm{S}$ produces crack nucleation in grain $\mathrm{R}$ via stress wave interaction.

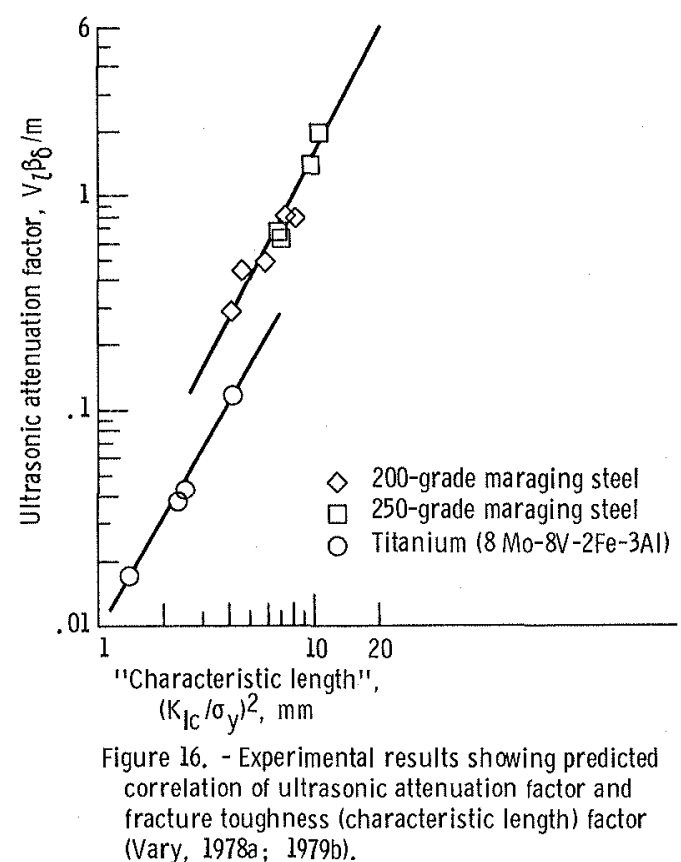




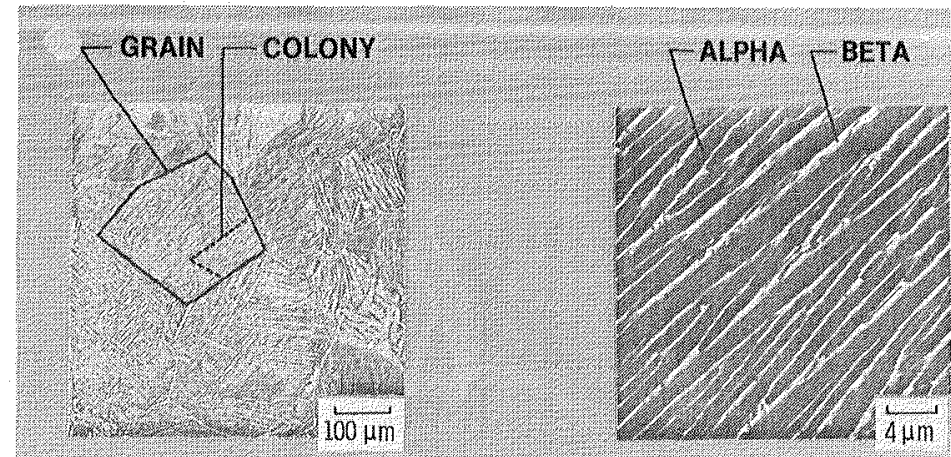

\section{GRAIN/SUBSTRUCTURE}

PHASE STRUCTURE

Figure 17. - Photomicrographs of two-phase titanium alloy showing three levels of microstructure (Vary and Hull, 1982).

C-82-3721
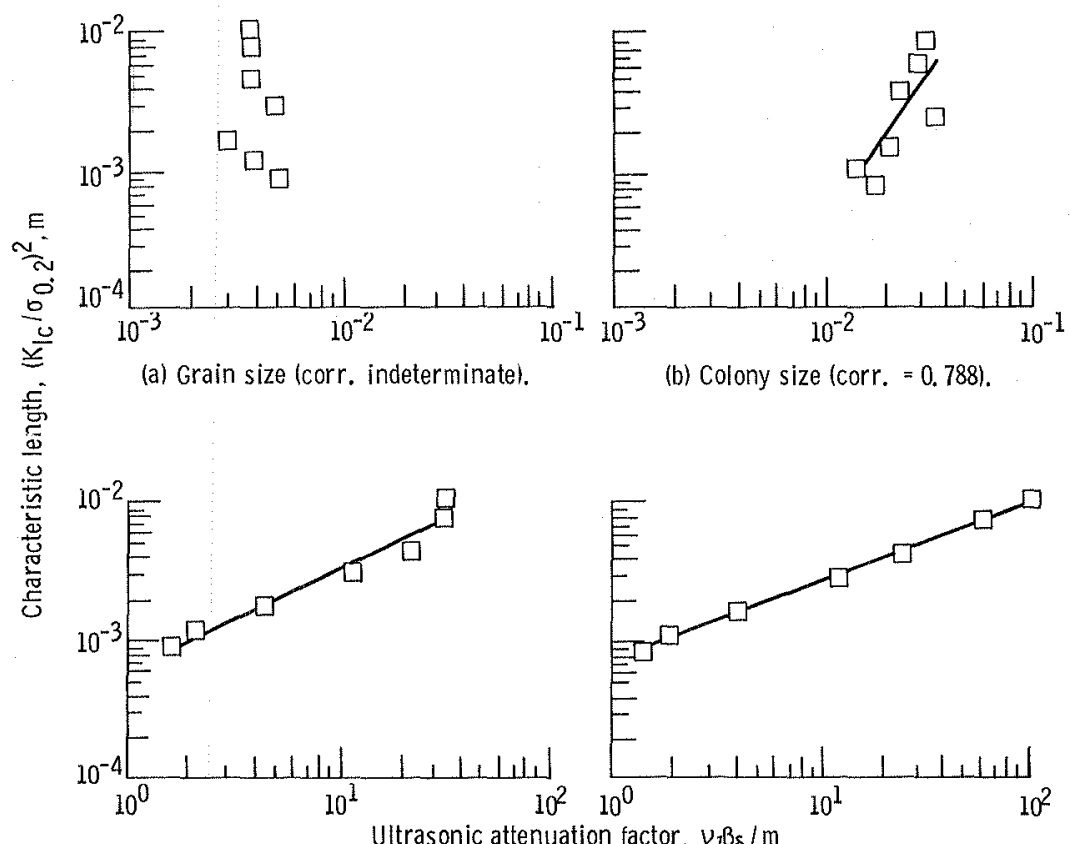
(c) Alpha phase thickness (corr. $=0.977$ ).

(d) Beta phase thickness (corr. $=0.998$ ).

Figure 18. - Comparis on of foughness (characteristic length) and attenuation factors for four microstructural features in a two-phase titanium alloy (Vary and Hull, 1982). 


\begin{tabular}{|c|c|c|c|c|}
\hline $\begin{array}{l}\text { 1. Report No. } \\
\text { NASA TM- } 86876\end{array}$ & \multicolumn{2}{|c|}{ 2. Government Accession No. } & \multicolumn{2}{|c|}{ 3. Recipient's Catalog No. } \\
\hline \multirow{2}{*}{\multicolumn{3}{|c|}{$\begin{array}{l}\text { 4. Title and Subtitle } \\
\text { Ultrasonic Nondestructive Evaluation, Microstructure, } \\
\text { and Mechanical Property Interrelations }\end{array}$}} & \multicolumn{2}{|c|}{$\begin{array}{l}\text { 5. Report Date } \\
\text { October } 1984\end{array}$} \\
\hline & & & \multicolumn{2}{|c|}{$\begin{array}{l}\text { 6. Performing Organization Code } \\
506-53-1 \mathrm{~A}\end{array}$} \\
\hline \multicolumn{3}{|l|}{ Alex Vary } & \multicolumn{2}{|c|}{$\begin{array}{l}\text { 8. Performing Organization Report No. } \\
E-2337 \\
\end{array}$} \\
\hline \multicolumn{3}{|c|}{ 9. Performing Organization Name and Address } & \multirow{2}{*}{\multicolumn{2}{|c|}{ 11. Contract or Grant No. }} \\
\hline \multicolumn{3}{|c|}{$\begin{array}{l}\text { National Aeronautics and Space Administration } \\
\text { Lewis Research Center } \\
\text { Cleveland, Ohio } 44135\end{array}$} & & \\
\hline \multirow{2}{*}{\multicolumn{3}{|c|}{$\begin{array}{l}\text { 12. Sponsoring Agency Name and Address } \\
\text { National Aeronautics and Space Administration } \\
\text { Washington, D.C. } 20546\end{array}$}} & \multicolumn{2}{|c|}{$\begin{array}{l}\text { 13. Type of Report and Period Covered } \\
\text { Technical Memo randum }\end{array}$} \\
\hline & & & \multicolumn{2}{|c|}{ 14. Sponsoring Agency Code } \\
\hline \multicolumn{5}{|l|}{ 15. Supplementary Notes } \\
\hline \multicolumn{5}{|c|}{$\begin{array}{l}\text { 16. Abstract } \\
\text { A selective review of ultrasonic techniques for mechanical property characteriza- } \\
\text { tions is presented and conceptual models are advanced for explaining and inter- } \\
\text { preting the empirically-based results. At present, the technology is generally } \\
\text { empirically based and is emerging from the research laboratory. Advancement of } \\
\text { the technology will require establishment of theoretical foundations for the } \\
\text { experimentally observed interrelations among ultrasonic measurements, mechanical } \\
\text { properties, and microstructure. Conceptual models are applied to ultrasonic } \\
\text { assessment of fracture toughness to illustrate an approach for predicting corre- } \\
\text { lations found among ultrasonic measurements, microstructure, and mechanical } \\
\text { properties. }\end{array}$} \\
\hline \multicolumn{5}{|c|}{ 17. Key Words (Suggested by Author(s)) } \\
\hline \multicolumn{2}{|c|}{$\begin{array}{l}\text { U1 trasonics; Nondestructive evaluation; } \\
\text { Mechanical properties; Microstructure; } \\
\text { Materials characterization }\end{array}$} & \multicolumn{3}{|c|}{$\begin{array}{l}\text { 18. Distribution Statement } \\
\text { Unclassi fied - unlimited } \\
\text { STAR Category } 38\end{array}$} \\
\hline $\begin{array}{l}\text { 19. Security Classif. (of this report) } \\
\text { Unclass i fied }\end{array}$ & $\begin{array}{l}\text { 2. Security Classif. (of th } \\
\text { Unclassi fiec }\end{array}$ & & 21. No. of pages & 22. Price ${ }^{*}$ \\
\hline
\end{tabular}

${ }^{\star}$ For sale by the National Technical Information Service, Springfield, Virginia 22161 


\section{End of Document}

